\author{
Federal Reserve Bank of New York \\ Staff Reports
}

\title{
Piggy Banks: Financial Intermediaries as a Commitment to Save
}

\author{
Donald P. Morgan \\ Katherine Samolyk
}

Staff Report No. 50

November 1998

Revised April 2013

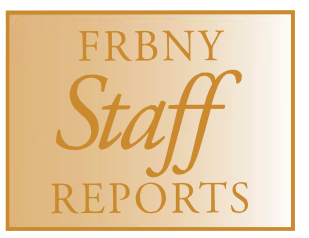

This paper presents preliminary findings and is being distributed to economists and other interested readers solely to stimulate discussion and elicit comments. The views expressed in this paper are those of the authors and are not necessarily reflective of views at the Federal Reserve Bank of New York or the Federal Reserve System. Any errors or omissions are the responsibility of the authors. 


\author{
Piggy Banks: Financial Intermediaries as a Commitment to Save \\ Donald P. Morgan and Katherine A. Samolyk \\ Federal Reserve Bank of New York Staff Reports, no. 50 \\ November 1998; revised April 2013 \\ JEL classification: E21, G21, G23
}

\begin{abstract}
Banks and other intermediaries may help savers commit to investment plans that savers could not stick to if they held assets directly. We illustrate this commitment function using a version of the Diamond and Dybvig (1983) model, where savers' short-run liquidity needs are correlated with shocks to investment opportunities. The investment securities are all freely tradeable, yet savers still do better if they delegate their investment decisions to an intermediary that overrides the savers' liquidity demands when investment opportunities warrant. Bank CDs, insurance annuities, pensions, and even social security, by locking funds out of reach, may all constitute real-world examples of this commitment role of financial intermediaries.
\end{abstract}

Morgan: Federal Reserve Bank of New York (e-mail: don.morgan@ny.frb.org). Samolyk: Federal Deposit Insurance Corporation (e-mail: ksamolyk@fdic.gov). The authors thank Michael Avery, Charlie Himmelberg, Robert Moore, and Kei-Mu Yi for helpful comments. The views expressed in this paper are those of the authors and do not necessarily reflect the position of the Federal Reserve Bank of New York or the Federal Reserve System. 


\section{Introduction}

Theorists have treated banks and other financial intermediaries as risk sharers, liquidity providers, and information producers. This paper introduces a fourth possible role: intermediaries can help savers commit to a savinginvestment plan that they (savers) could not stick to if they held securities directly. Not all savers may need "piggy banks," of course, but for certain savers at certain times the temptation to spend liquid assets may be irresistible. Locking funds in a bank certificate of deposit (CD), insurance annuity, or pension plan may provide a commitment value to some savers quite apart from, or in addition to, the other benefits associated with intermediated financial contracts.

We illustrate this commitment function using a version of the liquidity shock model in Bryant (1980) and Diamond and Dybvig (1983). The random demand for liquidity in that model forces savers to trade off returns and liquidity; the long-term asset pays more, but the short-term asset pays sooner. Intermediaries emerge to provide a form of liquidity insurance to savers by offering time-contingent deposit contracts that effectively shift some of the return on the long-term asset to the unlucky savers with short-term liquidity needs. ${ }^{1}$

Our version of the model is deliberately altered to highlight the value of intermediaries as a commitment device. Savers are less risk averse in our version so they have no demand for liquidity insurance or risk-sharing. Both assets are freely traded as well, so the delayed payoff on the long-term asset is not actually a problem; once a saver realizes his liquidity demand, he could simply trade assets with someone with the opposite demand. A third difference here is that the return on the short-term asset is random, either high or low. This assumption is key for our result, but fortunately it seems more plausible than the certain return usually assumed.

The commitment problem and "piggy bank" solution follow directly from the random return on the short-term asset, combined with savers' random liquidity needs. Ex ante, before investment returns and liquidity needs are realized, savers would optimally plan to reinvest some of their liquid assets in the short-term asset when the return on those assets turns out high. Ex post, savers with inelastic liquidity demands will decide to consume

\footnotetext{
${ }^{1}$ While this model was used initially to explore the reasons and effects for bank runs, it is now used more widely as a model of intermediation. See also Bernanke and Gertler (1987), Wallace (1990), and Hellwig (1994).
} 
all of their short-term assets instead of rolling them over. Left to their own devices, savers violate the standard intertemporal consumption condition, $U^{\prime}\left(c_{1}\right)=r U^{\prime}\left(c_{2}\right)$, by consuming too much, too soon when the interest rate $r$ turns out high. This commitment problem distorts savers' initial allocation of wealth between the two assets and that misallocation lowers the return to savings and savers' welfare. ${ }^{2}$

Savers can overcome their commitment problem, or at least reduce it, by locking their money in a bank before they are tempted to consume it, i.e., before liquidity needs are realized. These "piggy bank" intermediaries limit withdrawals in the high return state, thereby increasing the amount reinvested in those states. Savers with early liquidity needs lose ex post, of course, but they are better off ex ante by delegating investment decisions to an intermediary.

This commitment function is very different from the other roles attributed to intermediaries. Our intermediaries are certainly not providing risk sharing or insurance. In fact, consumption is more volatile with the "piggy bank" so its commitment function is valued only by savers who are not too risk averse. Nor are these intermediaries producing information; the assets here are more like public securities that savers could hold directly and trade freely as liquidity needs and interest rates change. Nor, finally, are these banks providing liquidity; in some sense the problem here is really too much liquidity, and the solution is too lock up funds in a intermediary that limits liquidity in some states.

Many real world intermediaries serve the basic commitment function of getting liquid assets out of peoples' hands before the more impulsive savers can spend at regrettable times. Pension funds, insurance annuities, mutual funds, and banks-the big four intermediaries-may all serve this commitment role, quite apart or incidentally to their more familiar roles. Many of the contracts these institutions sell to savers penalize the early withdrawal of funds one way or another (or in certain events) as do the intermediaries here. Bank CDs are the obvious example. Callable CDs, a recent bank innovation, even charge penalties that are effectively contingent on interest rates, very much like the contracts intermediaries offer here. ${ }^{3}$

\footnotetext{
${ }^{2}$ To be clear, the commitment problem in our model does not stem from time inconsistent preferences, as in Laibson (1997)

${ }^{3}$ Issuers can call the $\mathrm{CD}$ over a specified interval, either by paying off the CD holder or rolling it over at the new market rate. All else equal, banks will excercise the call when rates have fallen and pass when rates have risen, so the reinvestment decisions by banks
} 
The next section describes the saving environment and planners' solution. Section three contrasts that optimal plan to the allocation achieved when savers invest directly in securities and trade among themselves; we highlight the divergence from the optimal plan and show how the resulting portfolio distortions (between short and long-term assets) decrease with the degree of risk aversion. Section four shows how a financial intermediary can improve savers' welfare, even if the intermediary is not able to observe savers' true liquidity needs. We contrast the intermediary contract to a more complicated option-like arrangement where savers hold the long-term asset directly and buy the option to sell that asset contingent on their liquidity needs. We conclude in section five. Proofs are in the appendix in section six.

\section{The Savings Environment and Planner's So- lution}

The saving and investment environment is simple: savers are each endowed with one unit to invest in a short-term asset or a long-term asset at time zero to support consumption in period one or two. Like others, we assume savers are uncertain about their investment horizons. The only wrinkle in our set up is that long-term investors may want to re-invest their short-term assets.

We model uncertainty about investment horizons after Bryant (1980) and others. At time one, a fraction $\rho$ of savers will be forced to consume early, before the long-term asset pays off. If consumption in period $t$ is $c_{t}$, utility at time zero is

$$
U\left(c_{t}\right)= \begin{cases}U\left(c_{1}\right) & \text { with probability } \rho \\ U\left(c_{2}\right) & \text { with probability } 1-\rho,\end{cases}
$$

where $U^{\prime}() \geq$.0 and $U^{\prime \prime}() \leq$.0 . The liquidity shocks could be thought of as an irresistible impulse to consume, or as a drastic event, like illness or death, that forces savers to consume early. Allowing late consumers to substitute between period one and period two would not change our main results, but like the rest of the literature that uses these types of liquidity shocks, we need the assumption that early consumers cannot postpone consumption until period two. As in Hellwig (1994): "These (consumption) needs are inexorable ...there is no question of substitution between dates 1 and 2."

and spending decisions by savers will resemble those of our model to some extent. 
Consumption is supported by the yield from investments in short-term and long-term assets at time zero. Investing one unit in the short-term asset yields one in period one. The return at time one can be consumed or reinvested for another period at a rate that is random as of time zero. We discuss that random return momentarily.

Investing one unit in the long-term asset yields zero in period one and one in period two. ${ }^{4}$ Note that the long-term asset is illiquid only in the physical sense that it returns zero in period one; early consumers can trade their long-term assets for short-term assets, so the long-term asset is liquid in the financial sense. Much of the literature assumes the long-term asset can be physically liquidated (at a loss) but is not tradeable. We reverse those assumptions.

The key difference in our set up is that the second period return on the short-term asset is random:

$$
r_{i}= \begin{cases}r_{l}<1 & \text { with probability } \pi \\ r_{h} & \text { with probability } 1-\pi\end{cases}
$$

Savers learn the return in period one, at the same time they learn their investment horizon. On average, the long-term asset dominates the shortterm asset:

$$
\pi r_{l}+(1-\pi) r_{h}<1
$$

Savers still need to hold some short-term assets, however, in case they need to consume early. In most of the literature, liquidity insurance is the only reason savers hold the short-term asset. Savers here may want to hold the shortterm asset so they can roll them over in period one. The reinvestment option is valuable only if the short-term asset return on the high side dominates the long-term asset:

$$
r_{h}>1
$$

Assumption (1) is the fundamental difference in our set up. Most of the literature assumes the opposite inequality, or equivalently, that $\pi=1$. We merely allow some probability that short-term assets will dominate zerocoupon long-term assets if short-term rates rise sufficiently. We take these returns on these assets as given, primitive factors determined outside the model. The relative price of the assets, however, is determined through

\footnotetext{
${ }^{4}$ The assumption of unit returns is not essential, it just keeps the notation cleaner.
} 
trading, so the economy is in general equilibrium in the three solutions we consider: the planner's solution that we consider first, the decentralized market with direct investment and trading that we consider next, and the final, intermediated solution. 
The timeline below illustrates the sequence of investment, returns, and consumption

\begin{tabular}{|c|c|c|}
\hline \multicolumn{3}{|c|}{ Period: } \\
\hline 0 & 1 & 2 \\
\hline $\begin{array}{l}\text {-invest in short-term and } \\
\text { long-term assets }\end{array}$ & $\begin{array}{l}\text {-short-term asset pays } 1 \text { /unit } \\
\text { long-term asset returns } 0\end{array}$ & $\begin{array}{l}\text {-short-term asset pays } r_{j} / \text { unit } \\
\text { reinvested at time } 1\end{array}$ \\
\hline $\begin{array}{l}\text {-return on short-term asset in } \\
\text { period one is uncertain }\end{array}$ & $\begin{array}{l}\text {-learn return on short-term } \\
\text { asset: }\left(r_{h}>1>r_{1}\right)\end{array}$ & $\begin{array}{l}\text {-long-term asset pays } 1 / \text { unit } \\
\text { invested at time } 0\end{array}$ \\
\hline -consumption needs uncertain & $\begin{array}{l}\text {-learn consumption needs: } \\
\text { early consumers swap long- } \\
\text { term assets for short-term } \\
\text { assets with late consumers } \\
\text {-late consumers reinvest any } \\
\text { remaining short-term assets }\end{array}$ & $\begin{array}{l}\text {-late consumers "eat" return } \\
\text { on long-term assets and } \\
\text { reinvested short-term assets }\end{array}$ \\
\hline
\end{tabular}

\section{1}

Given the above saving environment, the planner at time zero collects each saver's unit and invests $s_{o}$ per saver in the short-term asset and $1-s_{o}$ per saver in the long-term asset. At time one, when the short-term rate $r_{i}$ is realized, the planner can reinvest some fraction $s_{i}$ of the short-term asset until time two. Reinvestment will be state contingent, hence the subscript. The planner also chooses consumption each period, and consumption will be state dependent as well. The first-period consumption constraint in state $i$ is

$$
c_{1 i}=\left(s_{o}-s_{i}\right) / \rho .
$$

Early consumers get the short-term investment, less the amount that gets reinvested until period two. Consumption gets scaled up by $\rho$ because the planner invests $s$ per saver but only the fraction $\rho$ consume early. Late consumers get the return on the long-term asset and on any short-term assets 
that were rolled over from the period one, hence the second period consumption constraint is

$$
c_{2 i}=\left(1-s_{o}+r_{i} s_{i}\right) /(1-\rho) .
$$

The only other constraint on the planner is that reinvestment in both states must be nonnegative:

$$
s_{i} \geq 0 \text {. }
$$

Subject to the three constraints above, the planner chooses $\left\{s_{0}, s_{i}, c_{1 i}, c_{2 i}\right\}$ to maximize the representative saver's expected utility at time zero:

$$
E U\left(c_{t i}\right)=\pi\left[\rho U\left(c_{1 l}\right)+(1-\rho) U\left(c_{2 l}\right)\right]+(1-\pi)\left[\rho U\left(c_{1 h}\right)+(1-\rho) U\left(c_{2 h}\right)\right] .
$$

Except for the state-contingent aspect, this is a straightforward programming problem. The first-order conditions can be combined as follows,

$$
\begin{aligned}
s_{i} \lambda_{i} & =0, \\
U^{\prime}\left(c_{1 l}\right)-r_{l} U^{\prime}\left(c_{2 l}\right) & =\lambda_{l} / \pi, \\
U^{\prime}\left(c_{1 h}\right)-r_{h} U^{\prime}\left(c_{2 h}\right) & =\lambda_{h} /(1-\pi), \\
(1-\pi)\left[U^{\prime}\left(c_{1 h}\right)-U^{\prime}\left(c_{2 h}\right)\right] & =\pi\left[U^{\prime}\left(c_{2 l}\right)-U^{\prime}\left(c_{1 l}\right)\right],
\end{aligned}
$$

where $\lambda_{i}$ is the multiplier on the constraint that $s_{i} \geq 0$. Conditions (3) and (4) are the combined first order conditions for $c_{t i}$ and $s_{i}$, while (5) is the first-order condition for $s_{o}$.

The planner's reinvestment strategy for the short-term asset is contingent on the rate realized at time one: if that rate turns out low, optimal reinvestment is zero; if it turns out high, reinvestment is positive (see appendix for proof). Since $s_{h}>0, \lambda_{h}=0$ so (4) implies

$$
U^{\prime}\left(c_{1 h}\right) / U^{\prime}\left(c_{2 h}\right)=r_{h}
$$

This standard intertemporal efficiency condition has the planner transfer goods from period one to period two (by rolling over the short-term asset) until the marginal (social) rate of substitution between the two types of consumers equals the marginal rate of transformation. Since $r_{h}>1$ then $c_{1 h}<c_{2 h}$ implying late consumers get more of the benefit from the high return on the short-term asset. On the other hand, $s_{l}=0$ implies $\lambda_{l}>0$, hence $c_{1 l}>c_{2 l}$; early consumer are compensated for their sacrifice in the 
high return state by higher consumption in the low return state. It turns out that when savers invest on their own, without the benefit of a planner or intermediary, they violate $(6) ; c_{1 h}$ is too high and $c_{2 h}$ is too low because of inadequate reinvestment when the short-term return turns out high. ${ }^{5}$

Substituting (6) into (5) yields

$$
\pi\left[U^{\prime}\left(c_{2 l}\right)-U^{\prime}\left(c_{1 l}\right)\right]=(1-\pi)\left[r_{h}-1\right] U^{\prime}\left(c_{2 h}\right) .
$$

This condition equates the marginal cost and benefit of investing in the shortterm asset. The left side is the opportunity cost of having invested in the short-term asset on the downside (when the future short-term rate turns out low); instead of reinvesting the short-term asset, the planner pays out the return to early consumers, raising their utility by $U^{\prime}\left(c_{1 l}\right)$. Had the planner invested in the long-term asset instead, he would have paid the unit return to the late consumers, which raises their utility by $U^{\prime}\left(c_{2 l}\right)$. Because $c_{2 l}<c_{1 l}$, the opportunity cost of the short-term asset on the downside is positive. ${ }^{6}$ The right side of (7) is the net marginal benefit of the short-term asset when the return turns out high. When the return is high, the planner reinvests the short-term asset and earns $r_{h}$. Had he invested more in the long-term asset at time zero he would have earned only 1, so the extra unit of short-term asset raises long-term consumers' utility by $\left(r_{h}-1\right) U^{\prime}\left(c_{2 h}\right)$. At the optimal portfolio, the marginal cost of the short-term asset on the downside (when the return is low) equals the marginal benefit on the upside (when the return is high.)

The optimal portfolio and consumptions are determined as follows. Since $s_{l}=0$ and $s_{h}>0$, consumption in the low return state depends only on $s_{0}$ while consumption in the high return state depends on reinvestment as well:

$$
\begin{aligned}
c_{1 l} & =s_{o} / \rho, \\
c_{2 l} & =\left(1-s_{o}\right) /(1-\rho), \\
c_{1 h} & =\left(s_{o}-s_{h}\right) / \rho, \\
c_{2 h} & =\left(1-s_{o}+r_{h} s_{h}\right) /(1-\rho) .
\end{aligned}
$$

\footnotetext{
${ }^{5}$ Since the short-term return on the deposit is random, the contract bears some resemblance the the lottery/deposits in Guillen and Tshoegl (2002), although the motivation for the random element is very different.

${ }^{6}$ The low short-term rate, $r_{l}$, does not enter the equation because the planner never invests at that rate; he pays out all the short-term asset in that state to early consumers.
} 
Substituting those equations into (6) and (7) determines the first best shortterm investment and the optimal amount of reinvestment in the high return state. That portfolio and reinvestment strategy then determine the first best consumptions.

\section{$3 \quad$ Direct Investment and Trading}

We now investigate whether savers can replicate the planner's solution on their own by choosing an initial portfolio at time zero and then trading assets at time one after liquidity needs and the next-period return on the short-term asset are realized. Fortunately, we only need to characterize the equilibrium to show where the decentralized solution violates the planner's allocation.

A few preliminary observations will simplify the analysis. Since savers are identical ex ante, they will choose the same initial portfolio at time zero. At time one, early consumers will want to swap their long-term assets for the short-term assets held by late consumers. The supply of long-term assets is inelastic, of course, as they are worthless to early consumers. The demand for the long-term asset, however, will depend on the realized rate on the shortterm asset, as that rate represents the opportunity cost to late consumers of trading their short-term assets.

Let $p_{i}$ denote the price of a unit of long-term asset in terms of the shortterm assets in interest rate state $i$. Early consumers get the return on their short-term asset, plus the income from selling their long-term assets to late consumers:

$$
c_{1 i}=s_{o}+p_{i}\left(1-s_{o}\right) .
$$

If late consumers each purchase $l_{i}$ units of long-term assets in period one in state $i$, reinvestment in the short-term asset is

$$
s_{i}=s_{o}-p_{i} l_{i}
$$

Reinvestment cannot be negative, hence

$$
s_{i} \geq 0
$$

This constraint also ensures that each late consumer has enough short-term assets to cover his purchases of long-term assets. 
Late consumers in state $i$ consume the return on their initial long-term assets, the long-term assets they purchase, and any left-over short-term assets that they rollover:

$$
c_{2 i}=1-s_{o}+l_{i}+r_{i} s_{i} .
$$

Savers choose $c_{t i}, s_{o}, l_{i}, s_{i}$, to maximize their expected utility at time zero, subject to the constraints above. The first order conditions for $c_{t i}, l_{i}, s_{i}$ can be combined as follows:

$$
\begin{aligned}
s_{i} \lambda_{i} & =0 \\
\left(1 / p_{l}-r_{l}\right) U^{\prime}\left(c_{2 l}\right) & =\lambda_{l} / \pi(1-\rho) \\
\left(1 / p_{h}-r_{h}\right) U^{\prime}\left(c_{2 h}\right) & =\lambda_{h} /(1-\pi)(1-\rho)
\end{aligned}
$$

These conditions pin down the relationship between reinvestment and the long-term asset price in a given state. If $s_{i}>0 \Rightarrow \lambda_{i}=0 \Rightarrow p_{i}=1 / r_{i}$; positive reinvestment in state $i$ implies the price of the long-term asset equals its discounted value in that state; the price could not be lower than $1 / r_{i}$ or late consumers would never reinvest at $r_{i}$. Conversely, if $p_{i}<1 / r_{i} \Rightarrow \lambda_{i}>$ $0 \Rightarrow s_{i}=0 \Rightarrow p_{i} l_{i}=s_{o}$; if the price of long-term asset is less than its discounted value, reinvestment is zero as long-term savers will trade all their short-term assets for long-term assets. These observations will be useful momentarily.

The first-order condition for $s_{o}$ is:

$$
\begin{gathered}
(1-\pi)\left[\rho\left(1-p_{h}\right) U^{\prime}\left(c_{1 h}\right)+(1-\rho)\left(r_{h}-1\right) U^{\prime}\left(c_{2 h}\right)\right]+\lambda_{h}= \\
\pi\left[\rho\left(p_{l}-1\right) U^{\prime}\left(c_{1 l}\right)+(1-\rho)\left(1-r_{l}\right) U^{\prime}\left(c_{2 l}\right)\right]-\lambda_{l} .
\end{gathered}
$$

The left side is the expected net benefit across periods of increasing $s_{o}$ by a unit in the event the short-term return is high. Early consumers get the unit return less the opportunity cost of having one fewer unit of long-term asset to sell in period one. If $p_{h}<1$, as it will be, increasing $s_{o}$ benefits early consumers. Late consumers also benefit on net since they can reinvest the unit at $r_{h}>1$. The additional benefit to late consumers is $\lambda_{h}$, the value of having more short-term assets to trade for long-term assets.

On the right is the benefit of having increased investment in the long-term asset when the return on the short-term asset is low. Note that if $p_{h}<1$, then it must be that $p_{l}>1$ or savers would not invest in the long-term asset 
in period zero. ${ }^{7}$ Since $p_{l}>1>r_{l}$, investing more in the long-term asset at time zero benefits both early consumers and late consumers in the low return state. The only minus, $\lambda_{l}$, is that late consumers would have fewer short-term assets to trade for long-term assets in period one.

In addition to these ex ante equilibrium conditions, the long-term asset market in period one must also clear in both interest rate states. Since the fraction $\rho$ of the population will each supply $1-s_{o}$ units of long-term assets at time one, the aggregate supply of long term assets is $\rho\left(1-s_{o}\right)$. The fraction $1-\rho$ of the population each purchase $l_{i}$ units of the long-term asset in state $i$, so aggregate demand for the long term asset is $(1-\rho) l_{i}$. Aggregate supply equals aggregate demand when

$$
\rho\left(1-s_{o}\right)=(1-\rho) l_{i}
$$

To determine if the spot market equilibrium matches the first best (planner's) solution, we conjecture an equilibrium like the first best and then check if the resulting consumption allocations are indeed first best. The key feature of the first best is that the planner reinvests in the short-term asset when short-term rates are high. Accordingly, we conjecture $s_{h}>0$, which implies

$$
p_{h}=1 / r_{h}<1 \text {. }
$$

At that price, consumption in the high return state is

$$
\begin{aligned}
& c_{1 h}=s_{o}+\left(1-s_{o}\right) / r_{h}, \\
& c_{2 h}=1-s_{o}+r_{h} s_{o}
\end{aligned}
$$

Late consumption turns out to be independent of the amount of reinvestment when the long-term asset sells for its full discounted value; late consumers are indifferent between reinvesting or buying long-term assets. Relative consumption in the high state is

$$
c_{1 h}=c_{2 h} / r_{h}
$$

For most preferences, this ratio will differ from the first best ratio determined by (6). Suppose

\footnotetext{
${ }^{7}$ They would expect to buy long-term assets on the cheap in period one, but would find that none were available, in which case the price would be unbounded, which contradicts $p_{l}<1$.
} 


$$
U(c)=\frac{c^{1-\alpha}}{1-\alpha}
$$

where higher $\alpha \in[0,1)$ indicates increasing risk aversion. Equation (16) then implies

$$
U^{\prime}\left(c_{1 h}\right)=r_{h}^{\alpha} U^{\prime}\left(c_{2 h}\right)<r_{h} U^{\prime}\left(c_{2 h}\right) .
$$

When savers invest directly at time zero, early consumption is higher than in the first best, which implies too little reinvestment. The inequality implies that the planner could raise welfare at time one by taking a unit from early consumers, reinvesting at $r_{h}$, and giving the proceeds to late consumers. Ex post, however, early consumers would not volunteer the unit since they will not be around to enjoy the higher second period consumption.

The less risk averse are savers, the greater the commitment problem and inefficiency associated with direct investing and trading. The ratio $c_{2 h} / c_{1 h}$ is independent of $\alpha$ when savers invest directly, but the first best ratio $c_{2 h} / c_{1 h}$ is decreasing in $\alpha$. Less risk averse savers are more flexible about shifting consumption toward period two in order to exploit the high return on the short-term asset.

We want to show later that savers' investment decisions are also distorted on the downside, so we need to characterize their allocations in the low interest state. Since reinvestment in the low state is zero in the first best, we also conjecture $s_{l}=0$. If late consumers do not reinvest in the low state, they must trade all their short-term assets for long term assets: $s_{o}-p_{l} l_{l}$. Using the latter to eliminate $l_{l}$ from (12) implies

$$
p_{l}=\frac{s_{o}(1-\rho)}{\rho\left(1-s_{o}\right)} .
$$

The price of the long-term asset in the low return state is increasing in the amount of the short-term asset, and in the fraction of late consumers. More short-term assets means late consumer have more to bid for long-term asset and fewer assets to bid on. More late consumers means more bidders and fewer sellers. Since $p_{l}>1,(18)$ implies $s_{o}>\rho$.

The equilibrium price, portfolio, and other variables are determined as follows. Given $s_{l}=0$, we know $c_{1 l}=s_{o} / \rho$ and $c_{2 l}=\left(1-s_{o}\right) /(1-\rho)$. Given $s_{h}>0$, we know $\lambda_{h}=0$ and $p_{h}=1 / r_{h}$. Substituting those values, (14), (15), and (9) into (11) produces an equation in $s_{o}$ and $p_{l}$. That equation and (18) determine the optimal short-term investment at time zero and the price 
that will result in period one. Those values then determine the consumption allocations. Given $s_{o}$, (12) determines $l_{h}$. Those variables and $p_{h}$ determine reinvestment in the high state: $s_{h}=s_{o}-p_{h} l_{h}$.

\subsection{Risk Aversion and Investment Distortions}

We noted in the introduction that savers' inability to exploit the high return on the short-term asset leads them to underinvest in the short-term asset. Their incentives are also distorted on the downside, when the short-term return is low, because the market price they face at time one differs from the shadow price the planner faces at time zero. These distortions are more severe when savers are less risk averse.

Savers underinvest in the short-term asset because the upside benefit is too low and the downside cost is too high. Savers' commitment problem prevents them from fully exploiting the high return, which lowers the upside benefit of the short-term asset. The opportunity cost of the short-term asset is too high on the downside because the long-term asset sells for more than one in that state.

We illustrate these distortions under the assumption of constant risk aversion. Even in that case, the extent of nonlinearity in the first order conditions precludes a closed form solution for $s_{o}$. Instead, we reduce the first order conditions to a single equation in $s_{o}$ and compare the properties of the solution equations in each case.

Using (6) to eliminate $s_{h}$ from (7) produces the solution equation for the first best:

$$
\pi f\left(s_{o}\right)=(1-\pi)\left(1-1 / r_{h}\right) j\left(r_{h}\right) g\left(r_{h} s_{o}\right),
$$

Let $s_{o}^{*}$ denote the solution to $(19)$. The $\pi$ on the left and the $(1-\pi)$ on the right indicate that the planner determines $s_{o}^{*}$ by weighing the downside against the upside. On the downside, the marginal opportunity cost of the short-term asset is

$$
f(.) \equiv\left(\frac{1-\rho}{1-s_{o}}\right)^{\alpha}-\left(\frac{\rho}{s_{o}}\right)^{\alpha} .
$$

This is the gain in utility from increasing long-term investment and giving the proceeds to late consumers; $f$ is positive (since $s_{o}>\rho$ ) and increasing in $s_{o}$. The benefit on the upside depends on

$$
g(.) \equiv 1 /\left(1+\left(r_{h}-1\right) s_{o}\right)^{\alpha},
$$


the gain in utility from increasing short-term investment, reinvesting at $r_{h}$, and paying the return to late consumers. Note that $g$ is decreasing in $s_{o}$.

The comparable equation for the market solution comes from substituting the equilibrium long-term asset price (12) into their first order (11) (plus the substitutions described above):

$$
\pi h\left(s_{o}\right)=(1-\pi)\left(1-1 / r_{h}\right) k\left(r_{h}\right) g\left(r_{h} s_{o}\right) .
$$

The marginal cost of the short term asset on the downside is

$$
h(.) \equiv\left[\left(1-s_{o}\right)\left(\frac{1-\rho}{1-s_{o}}\right)^{\alpha}+s_{o}\left(\frac{\rho}{s_{o}}\right)^{\alpha}\right]\left(\frac{s_{o}-\rho}{s_{o}\left(1-s_{o}\right)}\right) .
$$

Increasing $s_{o}$ has two partially offsetting effects on $h$. The term in square brackets is the sum of late consumers' and early consumers' marginal utility, weighted by the asset shares. Raising $s_{o}$ lowers this term since more weight is placed on early consumers, whose marginal utility declines with $s_{o}$. Increasing $s_{o}$ also increases the price of the long-term asset, however, which increases the opportunity cost of investing in the short-term asset. The net effect is positive, so $h$ is increasing in $s_{o}$

Comparing the benefits and costs reveals why savers underinvest in the short term asset. The only difference on the upside is between

$$
\begin{gathered}
j(.) \equiv\left(\rho r_{h}+(1-\rho) r_{h}^{1 / \alpha}\right)^{\alpha} \text { and } \\
k(.) \equiv \rho r_{h}^{\alpha}+(1-\rho) r_{h} .
\end{gathered}
$$

Because $x^{\alpha}$ is concave and $\rho<1, j>k .^{8}$. The upside is too low because savers reinvest too little. The difference on the downside for given $s_{o}$ is

$$
h\left(s_{o}\right)-f\left(s_{o}\right)=\left(p_{l}^{\alpha}-1\right)\left(\frac{\rho}{s_{o}}\right)^{\alpha+1},
$$

where $p_{l}$ is the price of the long term asset in the low interest rate state. The shadow price to the planner at time zero is one. Since $p_{l}>1$, the marginal cost of the short-term asset on the downside is too high. The high cost on the downside and the low benefit on the upside both cause savers to underinvest in the short-term asset.

\footnotetext{
${ }^{8}$ Let $x=r_{h}$ and $x^{\prime}=r_{h}^{1 / \alpha}$. Then $j=\left(\rho x+(1-\rho) x^{\prime}\right)^{\alpha}>\rho x^{\alpha}+(1-\rho) x^{\prime \alpha}=k$.
} 
Note that the distortions on each side are independent. Suppose savers had access to a better short-term asset with a higher upside return, $r_{h}$, but the same downside risk, $\pi$. The benefit increases with $r_{h}$ but the costs do not change. Suppose the upside on the new asset was high enough to compensate direct investors for their inability to fully exploit the high return. In this case, the upside benefit on the new asset to savers is equivalent to the upside benefit on the old asset to the planner. ${ }^{9}$ Savers would choose $s_{o}^{\prime}$ of the new short-term asset, less $s_{o}^{*}$, because the cost on the downside is still too high (relative to the planner).

The cost on the downside is too high because the asset will sell for more than one, the price to the planner. The high opportunity cost to savers leads them to underinvest in the asset. Note that if participation were limited, as in Diamond (1997), the long-term asset price would be lower and the distortion on the downside would be reduced.

The difference between the optimal portfolio and the savers' own portfolio is decreasing in the degree of risk aversion. The only case in which the distortion is zero is when $U=\ln c$. In that case, in which case (6) implies $c_{2 h}=r_{h} c_{1 h}$, the same as under direct investment. We stress this so it will be understood that financial intermediaries here are not providing insurance.

\section{Financial Intermediaries}

Delegating their investment decisions to an intermediary will almost always raise savers' expected utility and may give them the first best level of welfare. Savers deposit their wealth at time zero with the intermediary, who offers savers a two-period contract. The contracting problem facing the intermediary is the same as the allocation problem the planner solves except the intermediary cannot observe a savers' investment horizon at time one. ${ }^{10}$ Private investment horizons create an incentive problem: if short-term investors who must withdraw early earn too much, long-term investors will also with-

${ }^{9}$ If the upside on the new asset is $r_{h h}$, the benefit curves are coincident if:

$$
\left(1-1 / r_{h h}\right) k\left(r_{h h}\right) g\left(r_{h h} s_{o}\right)=\left(1-1 / r_{h}\right) j\left(r_{h}\right) g\left(r_{h} s_{o}\right) .
$$

\footnotetext{
${ }^{10}$ There are no fixed costs to intermediation so there is free entry. Competition among intermediaries ensures that the survivors must offer contracts that maximize savers' expected utility at time zero.
} 
draw early and reinvest until period two. To prevent this, the contract offered by the intermediary must satisfy the following incentive constraint:

$$
r_{i} c_{1 i} \leq c_{2 i}
$$

Because the intermediary's problem is a constrained version of the planner's, we only need to test if the additional constraint binds in the first best in either state. Savers' preferences will influence whether the constraints binds. If $U(c)=c^{1-\alpha} /(1-\alpha)$ and $\alpha<1$, the incentive constraint is slack in the high return state. With those preferences, (6) implies $c_{2 h}=r_{h}^{\alpha} c_{1 h}<r_{h} c_{1 h}$ so (21) is not binding. Positive reinvestment in the high return state shifts consumption toward period two, which relaxes the incentive constraint.

The incentive constraint may bind in the low state, however. The planner does not reinvest in that state, so the ratio $c_{1 l} / c_{2 l}$ may be high enough to violate (21). If so, the intermediary must reduce short-term investment and increase long-term investment. ${ }^{11}$ Substituting $c_{1 l}=s_{o} / \rho$ and $c_{2 l}=$ $\left(1-s_{o}\right) /(1-\rho)$ into $(21)$ determines the intermediary's maximum incentive compatible short-term investment:

$$
\overline{s_{o}}=\frac{\rho}{\rho+(1-\rho) r_{l}} .
$$

The upper limit on short-term investment falls as $r_{l}$ rises; a higher downside increases the return to reinvestment so the intermediary must reduce the amount available for late consumers to reinvest. Higher $\rho$ increases the upper limit because the short-term investment gets spread across more consumers.

The intermediary achieves the first best if $\overline{s_{o}}$ falls to the right of $s_{o}^{*}$. If $\overline{s_{o}}>s_{o}^{*}$, the downside cost of the short-term asset exceeds the upside benefit so the intermediary would not want to hold $\overline{s_{o}}$ in the first place. If $s_{o}^{*}>\overline{s_{o}}$, the intermediary cannot achieve the first best but he still dominates direct investment except when savers happen to choose $\overline{s_{o}}$ on their own. ${ }^{12}$

\footnotetext{
${ }^{11}$ Reinvesting in the short-term asset would also relax the incentive constraint, but investing more in the long-term asset is the most efficient way to raise second period consumption. Reinvestment is determined by (6) even if the incentive constraint binds.

${ }^{12}$ Evaluating (19) at $\overline{s_{o}}$ produces a condition on the parameters that determines whether the intermediary achieves the first best:

$$
\begin{aligned}
s_{o}^{*} & \lessgtr \overline{s_{o}} \Longleftrightarrow \\
\frac{\pi\left(1 / r_{l}^{\alpha}-1\right)}{\left(\rho r_{h}+(1-\rho) r_{l}\right)^{\alpha}} & \gtrless(1-\pi)\left(1-1 / r_{h}\right) j\left(r_{h}\right) .
\end{aligned}
$$
}


Our intermediaries serve a very different role from the banks in Diamond and Dybvig (1983). The intermediaries in their model shift the relatively higher return from longer-term assets to early consumers, which allows smoother consumption. The intermediaries here do just the opposite; they allow savers to exploit temporary high returns and to shift consumption from early in life to later in life, which causes more variable consumption.

\subsection{Necessary conditions for intermediation}

Uncertainty about the timing of consumption needs is necessary before savers need an intermediary. If there is only uncertainty about returns, but not about the timing of consumption needs, savers can do just as well by investing directly. Suppose savers know when they will need to consume in either period one or two. The solution is trivial; if all savers are early consumers $(\rho=1)$, they invest only in the short-term asset. If all savers are late consumers $(\rho=0)$, they will invest only in the long-term asset since it has the highest expected return. In this case there is obviously no need for an intermediary.

Intermediaries are necessary only if early consumers get zero utility from later consumption. Only in that extreme case are savers completely unwilling ex post to substitute late consumption for early consumption. Suppose instead that savers get utility from consuming in both periods, but we define early consumers as people with relatively high marginal rates of substitution between early and late consumption, $U^{\prime}\left(c_{1}\right) / U^{\prime}\left(c_{2}\right)$. In that case, savers could still invest directly in the short-term asset. After they learn rates, both types would set $U^{\prime}\left(c_{1}\right) / U^{\prime}\left(c_{2}\right)=r_{2}$. Consumption allocations would differ, but with the marginal rate of substitution for each type equal to the marginal rate of transformation ex post, there are no gains to locking up the short-term asset with an intermediary. Putting it differently, savers would make the same investments in period one that they would make in period zero, so there is no commitment problem, and no need for an intermediary.

The contract offered by the intermediary here resembles the callable CDs now sold by real-world banks. ${ }^{13}$ Callable CDs give banks' a prepayment option, i.e., they can pay off before the stated maturity date. The option may exist only for the first year of the contract, or until maturity. Bankers'

\footnotetext{
${ }^{13}$ See Certificates of Deposits: Tips for Investors,http://www.sec.gov/consumer/certific.htm These callable CDS differ from the market indexed CDs analyzed by Chen and Kensigner (1990).
} 
decision whether to call a CD and the CD holders' spending will depend on market rates much like the contract and consumption allocations modelled here. If market rates fall (relative to initial CD rate), banks will tend to call CDs and the holders will tend to spend more (rather than rollover their savings at the lower rate). If market rates rise, banks will be less inclined to call CDs, and the holders will postpone consumption. The motivations for the real-world contract and ours may differ, but the effects are similar.

\subsection{Another option}

As in Boyd and Prescott (1986), the intermediary in our model is essentially a contract among a coalition of savers. The contract is not unique. Savers could invest directly in the long term asset and buy an option to sell it the next period in case they need to consume early. This would solve the essential purpose of the intermediary: locking up the liquid asset out of reach of early consumers. This forward market does as well as the intermediary, but the arrangement is certainly more complicated.

The option market works as follows. In period one, investors divide their wealth between the short term asset and the long term asset. They can also buy an option at time zero to sell the long-term asset in period one in state $i$ for a price of $q_{i}$. Late consumers get a rebate of $R_{i}$. Savers pay a dealer a fee of $f$ at time zero for this option. The dealer invests the fee in the short-term asset. Fee revenues must be sufficient to buy up all the early consumers long-term assets. Any excess revenue is reinvested in the short-term asset. The proceeds from reinvestment are rebated to late consumers, along with the long-term assets purchased from early consumers.

We can show that the equilibrium contract can deliver the first-best by manipulating the budget constraints of the consumers and dealers. ${ }^{14}$ The "trick" is to show that combined constraints on savers and the dealers reduce to the consumption constraints on the planners' problem. This option

\footnotetext{
${ }^{14}$ Since the option dealer cannot observe the savers' type, he faces the same incentive constraint as the intermediary. This condition ensures that late consumer will not exercise the option and then reinvest the proceeds in the short-term asset. This constraint will be just as tight under the option market as under the intermediary. Since the option price will differ from the price that would prevail on the spot market, late consumer might also have an arbitrage opportunity; they could exercise the option to sell their long-term assets and then repurchase them from early consumers on the spot market. But the spot market will never open. If $q_{i}<p_{i}$, long-term consumers would not want to buy on the spot market. And if $q_{i}>p_{i}$, early consumers not want to sell on the spot market.
} 
contract gives early consumers

$$
c_{1 l}=q_{i}\left(1-s_{o}\right)+s_{o} .
$$

The dealer must collect enough in fees to purchase the long term assets from the $\rho$ households that want to sell in period one: $f \geqslant \rho q_{i} l_{o}$. Let $s_{i}$ denote any excess fees that are reinvested in the short-term asset. The dealer's first period constraint is

$$
s_{i} \equiv f-\rho q_{i} l_{o} \geqslant 0 .
$$

Eliminating $q_{i} l_{o}$ from these two equations implies

$$
\rho c_{1 i}=f-s_{i}+\rho s_{o} .
$$

Consumption by late consumers is

$$
c_{2 i}=1-s_{o}+r_{i} s_{o}+R_{i}
$$

The dealer must earn enough on reinvestment and the long-term assets they buy in period one to pay this rebate to the $1-\rho$ households that consume late:

$$
(1-\rho) R_{i}=r_{i} s_{i}+\rho\left(1-s_{o}\right) .
$$

Eliminating $R_{i}$ from these two equations implies

$$
(1-\rho) c_{2 i}=1-s_{o}+r_{i} s_{i}+(1-\rho) r_{i} s_{o}
$$

Note that if $s_{o}=0$, the consumption constraints (22) and (23) are the same as in the planner's problem. Let $s^{*}$ denote the first best level of investment in the short-term asset. The solution to the option contract is the same, as long as $f=s^{*}$. The crucial feature of the solution is that savers do not hold the short-term asset directly. This prevents them from consuming the proceeds if they need to consume early. Direct investment in the long-term asset poses no problems because savers cannot consume that asset prematurely.

Unlike the intermediary, which invests in both the short-term and longterm asset in period zero, the option dealer would invest only in the shortterm asset at time zero. The dealer equilibrium is still intermediated in some sense, however, because savers never invest directly in the short-term asset, nor do they trade assets among themselves. 


\section{Conclusion}

Apart from their roles as diversifiers, information producers, and liquidity providers, financial intermediaries may serve a more basic "piggy bank" function for savers. Locking funds in an intermediary, whether a bank CD, a pension plan, or an insurance annuity, may help some savers stick to long-term plans that they could not commit to if they held funds directly. Obviously, these intermediaries attract funds for other reasons, namely the higher return they may offer. Our point is that the illiquidity premium demanded by some savers may not be as large as one might expect, since for some savers, illiquidity may be a blessing in disguise. 


\section{References}

[1] Allen, Franklin (1997), "Financial Markets, Intermediaries, and Intertemporal Smoothing," Journal of Political Economy, 105 (3), pages 523-46.

[2] Barro, Robert J (1997) "Myopia and Inconsistency in the NewClassical Growth Model," National Bureau of Economic Research, Working paper \# 6317.

[3] Bernanke, Ben and Mark Gertler (1987) "Banking in General Equilibrium" in New Approaches to Monetary Economics, edited by William A. Barnett and Kenneth J. Singleton. New York, Cambridge University Press.

[4] Boyd, John H. and Edward C. Prescott (1986) "Financial Intermediary Coalitions," Journal of Economic Theory, 38, 211-232.

[5] Bryant, J (1980) "A Model of Reserves, Bank Runs, and Deposit Insurance," Journal of Banking and Finance, 4, 335-344.

[6] Chen, Andrew and John W. Kensinger (1990) "An Analyisis of MarketIndexed Certificates of Deposit," Journal of Financial Services Research

[7] Diamond, Douglas, W. (1984) "Financial Intermediation and Delegated Monitoring," Review of Economic Studies, 51, 393-414.

[8] Diamond, Douglas, W. and Philip Dybvig (1983) "Bank Runs, Deposit Insurance, and Liquidity." Journal of Political Economy, 91 401-19.

[9] Diamond, Douglas, W. (1997) "Liquidity, Banks, and Markets," Journal of Political Economy, 105, 928-956.

[10] Guillen, Mario and Adrian Tshoegl (2002) "Banking on Gambling: Banks and Lottery Linked Accounts," Journal of Financial Services Research, 21:3, 219-231

[11] Hellwig, Martin, "Liquidity Provision, Banking, and The Allocation of Interest Rate Risk," European Economic Review, (August 1994), 136389. 
[12] Holmstrom Bengt and Jean Tirole (1998) "Private and Public Supply of Liquidity," Journal of Political Economy, 1-40.

[13] Laibson, David. (1997) "Golden Eggs and Hyperbolic Discounting," Quarterly Journal of Economics, 117, 443-478.

[14] Wallace, Neil (1990), "A Banking Model Where Partial Suspension is Best," Quarterly Review, Federal Reserve Bank of Minneapolis, 11-23

\section{Appendix}

This appendix states and proves four lemmas useful in simplifying the planner's first order conditions for the optimal investment and consumption allocations.

Lemma $1 s_{l}>0 \Rightarrow s_{h}>0$. Proof: assume $s_{l}>0 ; s_{h}=0$. Then $c_{1 l}>c_{2 l}$ and $c_{1 h}<c_{2 h}$. It follows from $c_{1 l}>c_{2 l}$ and $r_{l}<1$ that $(1-\rho) / \rho>(1-$ $\left.s_{0}+r_{1} s_{l}\right) /\left(s_{0}-s_{l}\right)>\left(1-s_{0}\right) / s_{0}$ but $c_{1 h}<c_{2 h} \Rightarrow(1-\rho) / \rho>\left(1-s_{0}\right) / s_{0}, a$ contradiction.

Lemma $2 s_{l} \Rightarrow c_{1 l}>c_{21}$ by (2) and (3) while $s_{h}=0 \Rightarrow c_{1 h}<c_{2 h}$ by (2) and (4). $c_{1 l}>c_{21}$ and $r_{l}<1 \Rightarrow(1-\rho) / \rho>\left(1-s_{0}+r_{1} s_{l}\right) /\left(s_{0}-s_{l}\right)>\left(1-s_{0}\right) / s_{0}$ while $c_{1 h}<c_{2 h}$

$\Rightarrow(1-\rho) / \rho<\left(1-s_{0}\right) / s_{0}$, a contradiction.

Lemma $3 s_{l}>0 \Rightarrow c_{2 l}<c_{2 h}$. Proof: assume $s_{l}>0 ; c_{2 l}>c_{2 h}$.

Since $c_{2 l}<c_{1 l}$ and $c_{2 h}>c_{1 h}$ (by lemma 1), $c_{2 h}<c_{2 l} \Rightarrow c_{1 l}>c_{1 h}$.

But $c_{2 i}>c_{2 h} \Rightarrow r_{h} s_{h}<r_{l} s_{l} \Rightarrow s_{l}>s_{h} \Rightarrow c_{1 l}<c_{1 h}$, a contradiction.

Lemma $4 s_{l}=0$. Proof: $s_{l}>0 \Rightarrow s_{h}>0$ (by Lemma 1), hence $\lambda_{l}=\lambda_{l}=0$. Conditions (3), (4), and (5) $\Rightarrow(1-\pi)\left(r_{h}-1\right) / \pi\left(1-r_{l}\right)=U^{\prime}\left(c_{2 l}\right) / U^{\prime}\left(c_{2 h}\right)>$ 1(by Lemma 2), which is a contradiction, as $r_{h}<1$.

Lemma $5 s_{h}>0$. Proof: Suppose $s_{h}=s_{l}=0 \Rightarrow c_{1 l}=c_{1 h} \equiv c_{1}$ and $c_{2 l}=$ $c_{1 h} \equiv c_{2}$. Condition (5) $\Rightarrow U^{\prime}\left(c_{1}\right)=U^{\prime}\left(c_{2}\right)$, while (5) $\Rightarrow U^{\prime}\left(c_{1}\right)>U^{\prime}\left(c_{2}\right)$, a contradiction. 